\title{
Multiple Re-treatments with Atosiban, an Oxytocin Receptor Antagonist Helps to Delay the Preterm Labor Successfully
}

\section{Kedar N Ganla, Priyanka H Vora*, Rana A Choudhary, Manjusha K Ganla, Prajkta Joshi and Kavita Desai}

Department of Reproductive Medicine, Ankoor Fertility Clinic, Mumbai, Maharashtra, India

*Corresponding Author: Priyanka H Vora, Department of Reproductive Medicine, Ankoor Fertility Clinic, Mumbai, Maharashtra, India.
Received: March 10, 2021

Published: April 12, 2021

(C) All rights are reserved by Priyanka $\mathbf{H}$

Vora., et al.

\begin{abstract}
Assisted reproduction technology (ART) for infertile couples is strongly associated with twinning and twins remain a high-risk group for preterm labor as compared with singletons. Atosiban is used for the management of preterm labor and threatened abortion cases. Re-treatment with atosiban is possible ( $\leq 3$ cycles), but there is only limited clinical experience available with multiple retreatment cycles. Herein, we report the case where 4 full course re-treatment cycles with atosiban (tocolytic) were used successfully to delay the preterm labor in the same gestation. A 33-year-old female patient with twin pregnancy conceived via Intracytoplasmic Sperm Injection (ICSI) presented with preterm labor with vigorous uterine contractions. She was administered with continuous 48hour intravenous atosiban infusion (full course) on 4 different occasions at 28, 28.5, 30.4 and 31.4 weeks of gestation. The gestation of women who reported preterm labor at $28^{\text {th }}$ week, was extended to $34^{\text {th }}$ week by repeated use of Atosiban treatment cycles. At 34 weeks, due to leaking per vaginum an emergency caesarean section was performed to deliver two live, premature babies weighing $2.1 \mathrm{~kg}$ and $1.5 \mathrm{~kg}$, respectively. In our experience, comparing to other tocolytic agents, atosiban multiple re-treatment cycles successfully help to delay the preterm labor and presents no safety concerns for either mother or fetus in twin pregnancy.
\end{abstract}

Keywords: Atosiban; Preterm Labor; Tocolysis; Twin Gestation; Case Report

\section{Abbreviations}

ICSI: Intracytoplasmic Sperm Injection; CRP: C-Reactive Protein; EFW: Estimated Fetal Weight; NICU: Neonatal Intensive Care Unit

\section{Introduction}

Preterm birth is the most common cause of perinatal morbidity and mortality. The incidence of preterm birth in India is $7-9 \%$ with a continuous upward trend. Challenges associated with prematurity put a humongous burden on the limited resources especially in a developing country like India [1]. The incidence of preterm birth is high in women with assisted reproduction (76.23\%). Multiple gestation further adds to this risk (45.1\%) especially in a country like India, where twin pregnancies are associated with three times greater risk of perinatal mortality as compared to singletons [2]. We, herein, report a case of successful use of 4 multiple re-treatment cycles of atosiban (tocolytic) to delay the preterm labor in twin pregnancy.

\section{Case Report}

A 33-year-old female, primigravida with twin gestation, achieved her first pregnancy by Intracytoplasmic Sperm Injection (ICSI). Prior to this, 8 years into her active married life, she suffered from infertility due to male factor infertility and patient was registered under our antenatal care. The pregnancy progressed uneventfully until 28 weeks of gestation when she went into spontaneous preterm labour. 
She was admitted and on clinical examination she was afebrile with a pulse rate of 100 beats per minute (tachycardia), while other clinical parameters were within normal limits. There was good fetal heart activity with vigorous uterine contractions and vaginal examination showed an uneffaced cervix, closed cervical os with Bishops score of 0. On admission, her hemoglobin was 11.5 gm\%, WBC 8800 with adequate platelets and elevated C- Reactive protein (CRP) of $9.4 \mathrm{mg} / \mathrm{dl}$. She had normal blood sugar level, thyroid profile and urine tests.

We administered her $12 \mathrm{mg}$ of Injection betamethasone at an interval of 24 hours. Simultaneously she was started on Atosiban (Tosiban, Zuventus Healthcare Ltd. Mumbai) for tocolysis. The standard protocol for atosiban administration was as follows: Atosiban injection $0.9 \mathrm{ml}$ bolus, immediately followed by a continuous loading infusion with $7.5 \mathrm{ml}$ of atosiban in $100 \mathrm{ml}$ Normal Saline for 3 hours. This was followed by a maintenance Atosiban infusion with $7.5 \mathrm{ml}$ in $500 \mathrm{ml}$ Ringer Lactate over 9 hours, followed by 4 more such infusions over a period of 45 hours in totality (Table 1).

\begin{tabular}{|l|c|c|c|}
\hline Step & Regimen & Infusion rate & $\begin{array}{c}\text { Atosiban } \\
\text { dose }\end{array}$ \\
\hline 1 & $\begin{array}{c}0.9 \mathrm{ml} \text { intravenous } \\
\text { bolus injection given } \\
\text { over } 1 \text { minute }\end{array}$ & Not applicable & $6.75 \mathrm{mg}$ \\
\hline 2 & $\begin{array}{c}3 \text { hours intravenous } \\
\text { loading infusion }\end{array}$ & $\begin{array}{c}24 \mathrm{ml} / \mathrm{hour} \\
(300 \mu \mathrm{g} / \mathrm{min})\end{array}$ & $54 \mathrm{mg}$ \\
\hline 3 & $\begin{array}{c}\text { Up to } 45 \text { hours sub- } \\
\text { sequent intravenous } \\
\text { infusion }\end{array}$ & $\begin{array}{c}8 \mathrm{ml} / \mathrm{hour}(100 \\
\mu \mathrm{g} / \mathrm{min})\end{array}$ & Up to $270 \mathrm{mg}$ \\
\hline
\end{tabular}

Table 1: Oxytocin receptor antagonist regimen (Atosiban).

After bolus injection, she responded to the treatment, experienced only light contractions, and the magnitude of uterine contractions subsided gradually with a marked reduction in uterine activity. The patient felt much relief from the pain and bearingdown sensation as uterine contractions completely subsided. Her colour Doppler ultrasound revealed twin gestation, with cervical length of $3 \mathrm{~cm}$ with $1^{\text {st }}$ Breech having an Estimated Fetal Weight (EFW) of $1.095 \mathrm{~kg}+/-100$ grams and $2^{\text {nd }}$ twin in Cephalic presentation having an EFW of $1.248 \mathrm{~kg}+/-120$ grams. Both fetuses had adequate growth intervals, liquor and normal doppler study.

However, she developed strong uterine contractions again at 28.5 weeks of gestation and a repeat full course of Atosiban in the same form was given and she responded to it. She was given a prophylactic antibiotic course in spite of a negative vaginal swab report. She was also put on weekly injectable progesterone depot. She was also given vaginal antibiotics and oral probiotics simultaneously.

Again at 30.4 weeks of gestation she went into preterm labour. Her blood counts showed no further increase in WBC counts and CRP levels. On vaginal examination the cervix was $1.5 \mathrm{~cm}$ dilated, $40 \%$ effacement with Bishops score of 1 . She was restarted on full course of injection Atosiban in the same regimen and the pain subsided after 2 days. She also received a rescue dose of betamethasone. Again at 31.4 weeks she had uterine contractions and the same atosiban management was repeated. She was asymptomatic after 2 days of intense monitoring.

However, at 34 weeks of gestation, she had leaking per vaginum and an emergency cesarean section was done after giving her Injection $\mathrm{MgSO}_{4}$ for neuroprotection. She delivered two male babies 2.1 $\mathrm{kg}$ and $1.7 \mathrm{~kg}$ respectively (Figure 1). The babies had APGAR score of $9 / 10$ and $8 / 10$ respectively. They were admitted to the neonatal intensive care unit (NICU) for 5 days in view of prematurity for observation and discharged subsequently. Also, intraoperatively, we did not have an atonic uterus or face any post-partum hemorrhage (intra and post-operative period was uneventful).

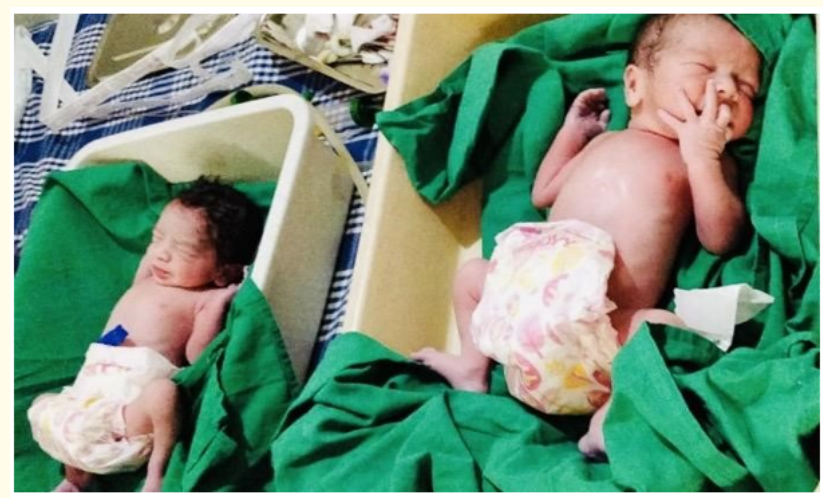

Figure 1: Twins at birth.

\section{Discussion}

With the increasing incidence of assisted reproduction there is a rise in the trend of preterm labour. Prematurity is a main con- 
tributor, with $50 \%$ of twin pregnancies delivering before 37 weeks and $10 \%$ delivering before 32 weeks of gestation. These advanced infertility treatments pose not only a psychological burden to the couple but also additional distress if the neonate lands up into the NICU, thus increasing morbidity and sometimes mortality rates [3]. Also, spontaneous preterm labor with intact membranes is responsible for approximately one third of all cases of preterm birth.

It is a well-known fact that oxytocin is a potent stimulant of myometrial contractility and its role in human parturition has been postulated. The clinical advantages of pregnancy prolongation even for a time frame of 7 days allows administration of corticosteroids or even permits transfer of the patient to an institution where intensive care facilities are available. Thus, interventions can reduce the risk of perinatal morbidity and mortality. Drugs which help to quieten the uterine contractility serve this very purpose [4].

Atosiban is an oxytocin-vasopressin receptor antagonist, capable of inhibiting oxytocin-induced uterine contractions, which has been shown in clinical studies to be an effective tocolytic with minimal side effects. It mainly helps in uterine quiescence. The duration of the treatment should not exceed 48 hours. The total dose given during a full course of atosiban therapy should preferably not exceed $330.75 \mathrm{mg}$ of atosiban. Maximum up to 3 re-treatments with atosiban have been used in literature [5]. However, even the fourth attempt was successful in our case. The plasma concentration of atosiban reaches a steady state one hour after the beginning of its infusion. During the first three hours of treatment, the number of contractions decreased by about 75\% [6]. Since it causes uterine relaxation, therefore postpartum bleeding and blood loss after delivery should be monitored. However, inadequate uterine contractions postpartum was not observed during clinical trials. Fetal side effects: Atosiban crosses the placenta in an average fetal versus maternal ratio of 0.124 . Drug concentrations in the fetal circulation do not increase with longer infusion rates, suggesting that the drug does not accumulate in the fetus. Maternal side effects: Most commonly reported adverse drug reactions (ADR) of atosiban are injection site reactions, headache, vomiting and nausea occurring in about $10 \%$ of the patients. In our patient nausea and mild headache which occurred were treated symptomatically $[7,8]$. Its use is contraindicated in patients with hypersensitivity to the active substance, premature rupture of the membranes $>30$ weeks of gestation, antepartum uterine hemorrhage, eclampsia and severe pre-eclampsia, suspected intrauterine infection, placenta praevia, abruptio placenta, any other conditions of the mother or fetus in which pregnancy continuation is hazardous.

There is limited literature regarding the use of atosiban in multiple pregnancies and re-treatment with atosiban ( $\leq 3$ cycles). Multiple pregnancy and medicinal products with tocolytic activity like calcium channel blockers and beta-mimetics are known to be associated with increased risk of pulmonary oedema and neonatal mortality [9]. Comparing to other tocolytic agents, because of its favourable safety profile, atosiban can be considered as the tocolytic agent of choice in patients with multiple pregnancy in preterm labour.

\section{Conclusion}

In patients with threatened preterm birth, multiple retreatment cycles with atosiban were found effective in preventing imminent preterm birth even when it was a twin pregnancy, where there is no fetal compromise or underlying maternal infection. Further, atosiban showed favorable side effects profile with even multiple treatment cycles of the drug in the same gestation. Also, increasing the mean gestational age at delivery by treating preterm labour can lead to a decrease in neonatal morbidity and mortality rates.

Therefore, as compared to traditional tocolytic agents, atosiban with fewer side effects may be helpful for prolongation of twin pregnancies conceived with use of Assisted reproductive technology.

\section{Bibliography}

1. Jamal Shehla and Ruchi Srivastava. "A retrospective analytical study of the epidemiology and causes of preterm birth". International Journal of Reproduction, Contraception, Obstetrics and Gynecology 6.12 (2017): 5453-5457.

2. Patil A., et al. "Preterm birth among pregnancies conceived by assisted reproduction techniques in Mumbai, Maharashtra, India”. International Journal of Reproduction, Contraception, Obstetrics and Gynecology 7.4 (2018): 1548-1553.

3. Murray Sarah R., et al. "Spontaneous preterm birth prevention in multiple pregnancy". The Obstetrician and Gynaecologist: the Journal for Continuing Professional Development from the Royal College of Obstetricians and Gynaecologists 20.1 (2018): 57-63. 
4. Romero R., et al. "An oxytocin receptor antagonist (atosiban) in the treatment of preterm labor: a randomized, doubleblind, placebo-controlled trial with tocolytic rescue". American Journal of Obstetrics and Gynecology 182.5 (2000): 1173-1183.

5. Husslein P., et al. "Clinical practice evaluation of atosiban in preterm labour management in six European countries". BJOG: An International Journal of Obstetrics and Gynaecology 113. 3 (2006): 105-110.

6. Kashanian, M et al. "Atosiban and nifedipin for the treatment of preterm labor". International Journal of Gynaecology and Obstetrics: The Official Organ of the International Federation of Gynaecology and Obstetrics 91.1 (2005): 10-14.

7. de Heus Roel., et al. "Management of preterm labor: atosiban or nifedipine?" International Journal of Women's Health 2 (2010): 137-142.

8. Valenzuela G J., et al. "Maintenance treatment of preterm labor with the oxytocin antagonist atosiban. The Atosiban PTL098 Study Group". American Journal of Obstetrics and Gynecology 182.5 (2000): 1184-1190.

9. Lamont Ronald F and Jan S Jørgensen. "Safety and Efficacy of Tocolytics for the Treatment of Spontaneous Preterm Labour". Current Pharmaceutical Design 25.5 (2019): 577-592.

\section{Assets from publication with us}

- Prompt Acknowledgement after receiving the article

- Thorough Double blinded peer review

- Rapid Publication

- Issue of Publication Certificate

- High visibility of your Published work

Website: www.actascientific.com/

Submit Article: www.actascientific.com/submission.php

Email us: editor@actascientific.com

Contact us: +919182824667 